\title{
The Sensor Kinase GacS Negatively Regulates Flagellar Formation and Motility in a Biocontrol Bacterium, Pseudomonas chlororaphis 06
}

\author{
Ji Soo Kim ${ }^{1 \dagger}$, Yong Hwan Kim ${ }^{2 \dagger}$, Anne J. Anderson ${ }^{3}$ and Young Cheol Kim ${ }^{1 *}$ \\ ${ }^{1}$ Institute of Environmentally-Friendly Agriculture, Chonnam National University, Gwangju 500-757, Korea \\ ${ }^{2}$ Korea Institute of Planning \& Evaluation for Technology on Food, Agriculture, Forestry \& Fisheries, Anyang 431-060, Korea \\ ${ }^{3}$ Department of Biology, Utah State University, Logan, UT, USA
}

(Received on November 7, 2013; Revised on January 3, 2014; Accepted on January 24, 2014)

The GacS/GacA two component system regulates various traits related to the biocontrol potential of plant-associated pseudomonads. The role of the sensor kinase, GacS, differs between strains in regulation of motility. In this study, we determined how a gacS mutation changed cell morphology and motility in Pseudomonas chlororaphis O6. The gacS mutant cells were elongated in stationaryphase compared to the wild type and the complemented gacS mutant, but cells did not differ in length in logarithmic phase. The gacS mutant had a two-fold increase in the number of flagella compared with the wild type strain; flagella number was restored to that of the wild type in the complemented gacS mutant. The more highly flagellated gacS mutant cells had greater swimming motilities than that of the wild type strain. Enhanced flagella formation in the gacS mutant correlated with increased expression of three genes, $f l e Q, f l i Q$ and $f l h F$, involved in flagellar formation. Expression of these genes in the complemented gacS mutant was similar to that of the wild type. These findings show that this root-colonizing pseudomonad adjusts flagella formation and cell morphology in stationary-phase using GacS as a major regulator.

Keywords : cell elongation, motility, stationary phase, two component regulation

Certain rhizobacteria are being studied as biopesticides to control plant pests because these strains possess beneficial traits to help plant health (Kim et al., 2011). Expression of these beneficial traits in the biocontrol strains is crucial

\footnotetext{
*Corresponding author.

These authors contributed equally to this study

Phone) +82-62-530-2071, FAX) +82-62-530-0208

E-mail)yckimyc@jnu.ac.kr
}

for their use in field conditions. The GacS/GacA (global antibiotic and cyanide sensor kinase/response regulator) two component system regulates the expression of a wide variety of traits in biocontrol pseudomonads (Kim et al., 2011). For example, production of antimicrobial factors such as phenazines and pyrollnitrin is impaired by a gacS mutation in the aggressive root colonizer Pseudomonas chlororaphis O6 (Park et al., 2011). In contrast, the gacS mutation in $P$. chlororaphis $\mathrm{O} 6$ increases production of the plant growth regulator, indole-acetic acid (Kang et al., 2006; Oh et al., 2013).

Root surface colonization is important for some bacteria to induce systemic acquired resistance to pathogens and to abiotic stresses (Cho et al., 2012; Kim et al., 2011). Our previous work demonstrates that mutants in $P$. chlororaphis O6 defective in root colonization did not induce resistance (Han et al., 2006). However, GacS regulation is not essential for the overall root colonization process (Chancey et al., 2002; Poritsanos et al., 2006; Schmidt-Eisenlohr et al., 2003).

Flagella are implicated in the association of bacteria with plant surfaces (O'Toole and Kolter, 1998). For example the binding of $P$. fluorescens F113 cells to root tips is correlated with a phenotype that improves swimming ability through altered flagella length. These phenotypes are complemented by the wild type gacS gene (Kusumoto et al., 2006, 2008). Movement in water channels is dependent on flagella rotation and leads to the use of low viscosity $0.3 \%$ agar to measure swimming motility (Rashid et al., 2000). In biocontrol pseudomonad strains, swimming motility is regulated differently by the GacS regulator. GacS negatively regulates motility in $P$. fluorescens (Martinez-Granero et al., 2006, 2012), but acts as a positive regulator in $P$. chlororaphis PA23 (Poritsanos et al., 2006).

To further understand the importance of different bacterial traits during rhizosphere colonization, the present study focused on flagella formation and cell morphology in 
the wild type, a gacS mutant and the complemented mutant of $P$. chlororaphis O6 (Spencer et al., 2003). Expression from genes involved in flagella synthesis was compared between strains to determine the effects of the gacS mutation on transcription.

Morphological changes of the gacS mutant. All strains used in the study were maintained as stocks in $15 \%$ glycerol at $-80^{\circ} \mathrm{C}$. Cells of $P$. chlororaphis $\mathrm{O} 6$ wild type, the gacS mutant and complemented gacS mutant were grown in Luria Broth (LB) for 2 days at $28^{\circ} \mathrm{C}$ to stationary-phase, and applied to glass slides before fixation and coating with gold-palladium alloy (Sigma-Aldrich Co., St. Louis, MO). The cells were imaged under a scanning electron microscope (Hitach S-2400, Hitach Co., Japan). Length and diameter in each bacterial strain was determined for at least 100 cells with two independent assays. Electron microscopy showed that the gacS mutant cells had elongated length when in stationary-phase as compared to the wild type or the complemented mutant (Fig. 1). Elongated growth of the gacS mutant was not apparent in log-phase cells (data not shown).

Effects of a mutation in $\operatorname{gacS}$ on motility. Inocula $\left(10^{6}\right.$ colony forming units in $10 \mu \mathrm{l}$ ) of the wild type, mutant and complemented mutant cells were transferred to the center of LB plate medium with $0.3 \%$ agar for swimming tests. The diameters of the colonies were recorded at $24 \mathrm{~h}$ to assess swimming ability (Fig. 2A). Swimming motility of the gacS mutant was significantly greater in $0.3 \%$ agar plates than that of the wild type or the complemented

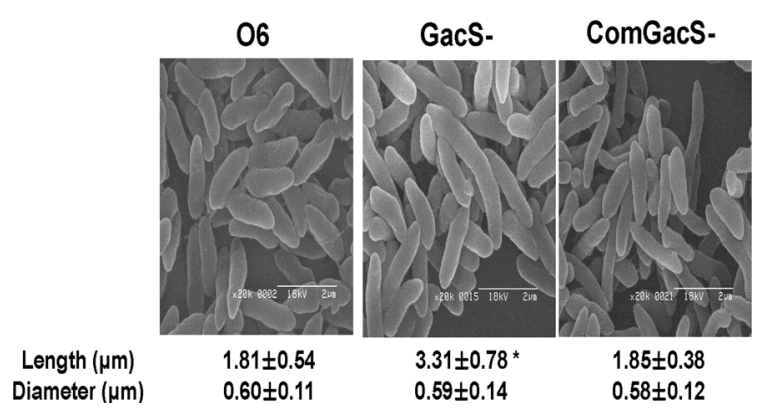

Fig. 1. Effect of mutation in gacS on morphology of stationaryphase cells of Pseudomonas chlororaphis O6. The wild type (O6), the gacS mutant (GacS-) and the complemented mutant (ComGacS-) were grown in LB to stationary-phase before imaging. Length and diameter for at least 100 cells for each strain were measured from the electron micrographs. The means and standard errors from two independent experiments are shown and the * indicates differences between the cell lengths as determined by Duncan's multiple range test at $P<0.01$.
gacS mutant, as shown by a $24 \%$ increase above that of wild type cells (Fig. 2A). The gacS mutant lacked orange pigmentation on the medium, because the quorum sensing system, conditioning phenazine formation, was impaired (Kang et al., 2007). Orange pigmentation due to phenazine production was observed in the wild type and the complemented-gacS mutant (Fig. 2A).

Because GacS regulates transcription of rpoS encoding a stress related sigma-factor (Kang et al., 2004), it seemed possible that RpoS was involved in the altered swimming
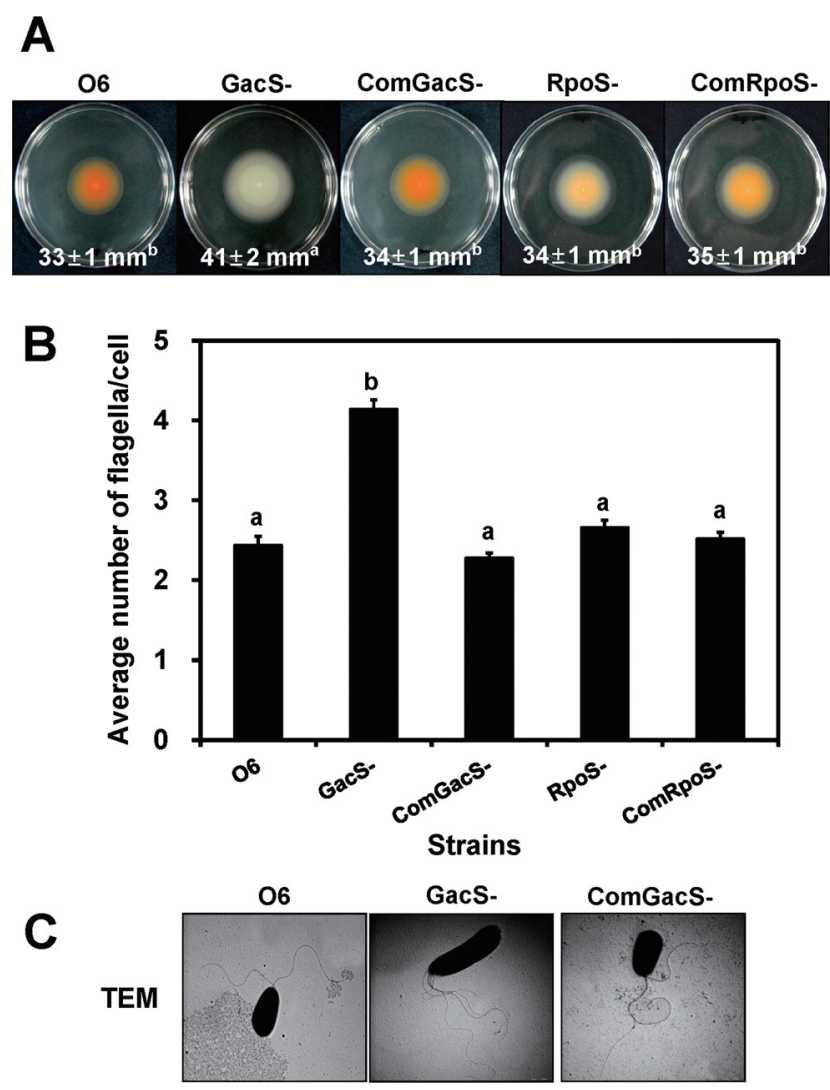

Fig. 2. Motility and flagellar formation of the Pseudomonas chlororaphis wild type (O6), the gacS mutant (GacS-), and the complemented gacS mutant (ComGacS-) under swimming conditions. Data for an rpoS mutant (RpoS-) and its complemented mutant (ComRpoS-) also are shown in A and B. (A) The growth medium contained $0.3 \%$ agar to assay swimming motility. Data with standard deviations in parentheses are means of three independent experiments with at least five plates for each strain. (B) Number of polar flagella for cells isolated from $0.3 \%$ agar. (C) Images generated by transmission electron microscopy (TEM) of the $P$. chlororaphis $\mathrm{O} 6$ cells grown to stationary phase in $0.3 \%$ agar when swimming would be feasible. Data are means of three independent experiments with observations from 50 different colonies in each strain. Different letters indicate significant differences among $P$. chlororaphis O6 strains by Duncan's multiple range test $(P<0.01)$. 
activity of the gacS mutant. Assay of swimming ability on $0.3 \%$ agar showed that the swimming ability of the rpoS mutant was unchanged from that of the wild type (Fig. 2A).

Increased flagellar formation in the gacS mutant. Cells from the $0.3 \%$ agar plates were removed for transmission electron microscopy (TEM) observations after their negative staining with a $2 \%$ aqueous solution of phosphotungstic acid (pH 7.4). A drop was applied onto a Formvar-carbon-coated grid, and the liquid was withdrawn after $30 \mathrm{~s}$ using filter paper. The samples were imaged under a JEOL JEM 1010 TEM (Jeol Inc., Tokyo, Japan) revealing the presence of an average of two lophotrichous flagella/cell for the wild type strain and the complemented gacS mutant (Fig. 2B). The average flagella number increased over two-fold in the gacS mutant cells. Similar measurements for the rpoS cells (Fig. 2B) showed that the number of flagella was statistically the same as that of the wild type confirming the finding that swimming ability was not enhanced in the rpoS mutant as was observed for the gacS mutant cells (Fig 2A). All flagella were located at one pole of the cell (Fig. 2A). These observations differed from $P$. fluorescens F113, in which a gacS mutation resulted in flagella elongation rather than a change in number (Martinez-Granero et al., 2012).

To determine whether flagella formation was being controlled by GacS with changes in transcription of genes involved in synthesis, we examined transcript accumulation from three genes, $f l e Q, f l i Q$ and $f l h F$. In $P$. aeruginosa, FleQ is a transcriptional regulator involved in flagella synthesis (Jyot et al., 2002). The small cytoplasmic membrane protein FliQ is proposed to be involved in an export pathway essential for flagella biosynthesis (Foynes et al., 1999). Loss of FlhF leads to abnormal numbers and placement of flagella in P. aeruginosa (Murray and Kazmierczak, 2006) and is now associated with a GTPase activity (Schniederberend et al., 2013). The complete genome sequence of $P$. chlororaphis $\mathrm{O} 6$ revealed a battery of genes with analogy to genes in other pseudomonads involved in flagella formation and function (Loper et al., 2012) including the genes selected for study: the locus encoding the transcriptional regulator (FleQ) was predicted at PchlO6_1727. The FliQ protein was encoded by locus PchlO6_1745 and the GTPase regulator, FlhF at PchlO6_1749. Total RNA from cells of the wild-type, the gacS mutant, and the complemented gacS mutant grown in King's B broth to stationary-phase was isolated using the RNeasy Mini kit (Qiagen Inc., Valencia, CA, USA) with the RNA Protect Bacteria reagent. The real timereverse transcription polymerase chain reaction (RT-PCR) was performed using the Brilliant Quantitative RT-PCR Master Mix (Stratagene Inc., La Jolla, CA, USA). A 25 $\mu 1$ mixture was incubated at $50^{\circ} \mathrm{C}$ for $30 \mathrm{~min}$ for reverse transcription, followed by RT-PCR using the specific primers: $f l h F$ gene, forward (5'-CGC ATG CAA CTG GAA AGT CT-3') and reverse (5'-GCA ACG CTT GTA GCT GTG GT- $3^{\prime}$ ), forward (5'-TCA ACG AAC AGA CCC TGA GC- $3^{\prime}$ ) and reverse (5'-CTG CCG TAC AAC TGC AGG AT- $\left.3^{\prime}\right)$ for the $f l i Q$ gene, and forward $\left(5^{\prime}-\mathrm{CCA}\right.$ GTT TTG TTA ATG GGC GA-3') and reverse (5'-TCT CAC GAT AGA CCT GGG CA-3') for the fle $Q$ gene. Specific primers for the $P$. chlororaphis O6 16S rRNA gene were: forward (5'-ATA CAG AGG GTG CAA GCG TT $-3^{\prime}$ ) and reverse (5'-CCG CTA CAC AGG AAA CTT CA $-3^{\prime}$ ) and expression from this gene was employed as the internal standard. A MX3000P Real Time PCR machine (Stratagene) was used for 25 cycles with denaturation at $94^{\circ} \mathrm{C}$ for 15 seconds, annealing at $55^{\circ} \mathrm{C}$ for 30 seconds, and a 30 second extension step at $72^{\circ} \mathrm{C}$. The PCR products were visualized on a $2 \%$ agarose gel. Using software from Stratagene, the comparative CT method $\left(2^{-\Delta \Delta C T}\right.$ method) was used to determine target gene expression which was normalized using 16S rRNA gene expression. Fold change in expression of the mutants was calculated by dividing normalized target gene expression values in the mutants by wild-type normalized expression values. Results are presented as mean and standard deviation of three replicates.

A comparison of RNA accumulation from these genes in wild type cells of $P$. chlororaphis O6, the gacS mutant, the complemented-gacS mutant is shown in Fig. 3. Accumulation of transcripts from $f l h F$ and $f l i Q$ was considerably higher in the gacS mutant than in the wild type and the complemented mutant. Although transcripts were detectable from $f l e Q$, the transcriptional activator, in all cell lines, they also were at higher levels in the gacS mutant. Thus, we found that expression from a putative export gene, $f l i Q$, as well as from two genes involved in different mechanisms for regulation of flagella formation, fle $Q$ and $f l h F$, were up-regulated in the gacS mutant compared with the wild type and complemented strains.

It is possible that an interaction occurs between the control system for flagella formation and cell division. The gacS mutant has abnormally elongated cell lengths, as determined by atomic force microscopy imaging (Anderson et al., 2005) and in this study for the stationary-phase cells. It is interesting that FlhF has GTPase activity (Balaban et al., 2009; Schniederberend et al., 2013). GTP hydrolysis is involved in FtsZ polymerization to form the ring during cell division (Mukherjee and Lutkenhaus, 1998). Additionally, FlhF activity is modified by FlhG and FlhG and interacts 

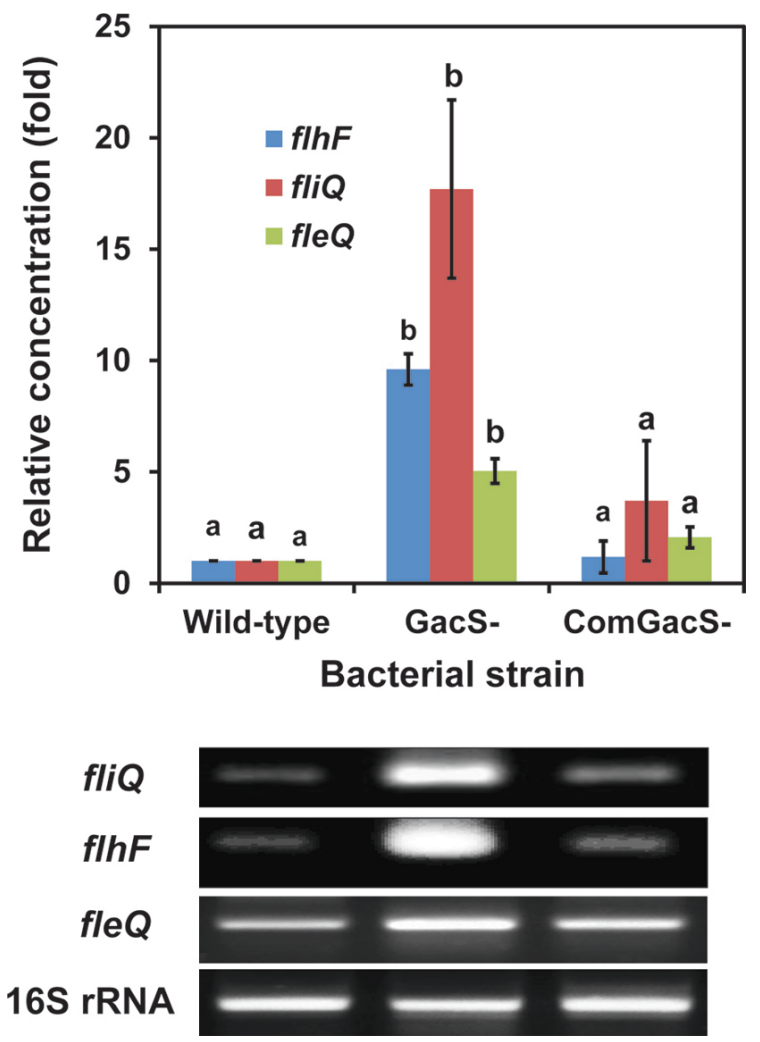

Fig. 3. A gacS mutation affects $f l e Q$, fli $Q$ and $f l h F$ transcript accumulation in Pseudomonas chlororaphis O6. Reverse transcription-polymerase chain reaction (RT-PCR) reactions were stopped at the end of the 15 th cycle, and PCR products were loaded on a $2.0 \%$ agarose gel. The intensity of the PCR products was used to measure relative transcript accumulations in cells of the wild type, the gacS mutant (GacS-), and the complemented GacS mutant (ComGacS-). Expression from the 16S rRNA genes was used to standardize transcript levels. Relative expression of the genes in P. chlororaphis $\mathrm{O} 6$ strains are means of three independent experiments, and different letters indicate significant differences in gene expression among $P$. chloraphis O6 strains according to Duncan's analysis of variance test $(P<0.05)$.

with FtsZ (Balaban and Hendrixson, 2011), inferring interactions between flagella formation and cell division. Furthermore, a master regulator of flagella biosynthesis and another cell surface feature, FleQ, is regulated by c-diGMP (Hickman and Harwood, 2008; Verstraeten et al., 2008), and altered FleQ regulation is a consequence of the gacS mutation in P. fluorescens 311 (Martinez-Granero et al., 2012; Navazon et al., 2009).

In summary, the greater swimming motility of the $P$. chlororaphis $\mathrm{O} 6 \mathrm{gacS}$ mutant correlated with the production of higher numbers of polar flagella and increased expression of genes concerned with flagella formation. Control by GacS was independent of the regulation by the alternative stress related sigma factor, RpoS. These findings add to the extensive role of traits already documented to be regulated by the Gac system in pseudomonads. In addition, these results add to the extensive phenotypic plasticity for microbial survival in soil and on plant roots where growth conditions are highly variable and Gac mutants arise spontaneously.

\section{Acknowledgments}

This study was supported by the Basic Science Research Program through the National Research Foundation of Korea (NRF) funded by the Ministry of Education, Science, and Technology (2011-0011555) and the Utah Agricultural Experimental Station.

\section{References}

Anderson, A. J., Britt, D. W., Johnson, J., Narasimhan, G. and Rodriguez, A. 2005. Physicochemical parameters influencing the formation of biofilms compared in mutant and wild-type cells of Pseudomonas chlororaphis O6. Water Sci. Technol. 52:21-25.

Balaban, M. and Hendrixson, D. R. 2011. Polar flagellar biosynthesis and a regulator of flagellar number influence spatial parameters of cell division in Campylobacter jejuni. PLoS Pathog. 7:e1002420.

Balaban, M., Joslin, S. N. and Hendrixson, D. R. 2009. FlhF and its GTPase activity are required for distinct processes in flagella gene regulation and biosynthesis in Campylobacter jejuni. J. Bacteriol. 191:6602-6611.

Chancey, S. T., Wood, D. W., Pierson, E. A. and Pierson, L. S. 2002. Survival of GacS/GacA mutants of the biological control bacterium Pseudomonas aureofaciens 30-84 in the wheat rhizosphere. Appl. Environ. Microbiol. 68:3308-3314.

Cho, S. M., Kang, B. R., Kim, J. J. and Kim, Y. C. 2012. Induced systemic drought and salt tolerance by Pseudomonas chlororaphis $\mathrm{O} 6$ root colonization is mediated by ABAindependent stomatal closure. Plant Pathol. J. 28:202-206.

Foynes, S., Dorrel, N., Ward, S. J., Zhang, Z. W., McColm, A. A., Farthing, M. J. and Wren, B. W. 1999. Functional analysis of the roles of FliQ and FlhB in flagellar expression in Helicobacter pylori. FEMS Microbiol. Lett. 174:33-39.

Han, S. H., Anderson, A. J., Yang, K. Y., Cho, B. H., Kim, K. Y., Lee, M. C., Kim, Y. H. and Kim, Y. C. 2006. Multiple determinants influence root colonization and induction of induced systemic resistance by Pseudomonas chlororaphis O6. Mol. Plant Pathol. 7:463-472.

Hickman, J. W. and Harwood, C. S. 2008. Identification of FleQ from Pseudomonas aeruginosa as a c-di-GMP-responsive transcription factor. Mol. Microbiol. 69:376-389.

Jyot, J., Dasgupta, N. and Ramphal, R. 2002. FleQ, the major flagellar gene regulator in Pseudomonas aeruginosa, binds 
to enhancer sites located either upstream or atypically downstream of the RpoN binding site. J. Bacteriol. 184: 5251-5260.

Kang, B. R., Cho, B. H., Anderson, A. J. and Kim, Y. C. 2004. The global regulator GacS of a biocontrol bacterium Pseudomonas chlororaphis $\mathrm{O} 6$ regulates transcription from the $r p o S$ gene encoding a stationary-phase sigma factor and affects survival in oxidative stress. Gene 325:137-143.

Kang, B. R., Han, S. H., Zdor, R. E., Anderson, A. J., Spencer, M., Yang, K. Y., Kim, Y. H., Lee, M. C., Cho, B. H. and Kim, Y. C. 2007. Inhibition of seed germination and induction of systemic resistance by Pseudomonas chlororaphis O6 requires phenazine production regulated by the global regulator, GacS. J. Microbiol. Biotechnol. 17:586-593.

Kang, B. R., Yang, K. Y., Cho, B. H., Han, T. H., Kim, I. S., Lee, M. C., Anderson, A. J. and Kim, Y. C. 2006. Production of indole-3-acetic acid in the plant-beneficial strain Pseudomonas chlororaphis $\mathrm{O} 6$ is negatively regulated by the global sensor kinase GacS. Curr. Microbiol. 52:473-476.

Kim, Y. C., Leveau, J., McSpadden Gardener, B. B., Pierson, E. A., Pierson III, L. S. and Ryu, C.-M. 2011. The multifactorial basis for plant health promotion by plant-associated bacteria. Appl. Environ. Microbiol. 77:1548-1555.

Kusumoto, A., Kamisaka, K., Yakushi, T., Terashima, H., Shinohara, A. and Homma, M. 2006. Regulation of polar flagellar number by the $f h F$ and $f h G$ genes in Vibrio alginolyticus. $J$. Biochem. 139:113-121.

Kusumoto, A., Shinohara, A., Terashima, H., Kojima, S., Yakushi, T. and Homma, M. 2008. Collaboration of FlhF and FlhG to regulate polar-flagella number and localization in Vibrio alginolyticus. Microbiology 154:1390-1399.

Loper, J. E., Hassan, K. A., et al. 2012. Comparative genomics of plant-associated Pseudomonas spp.: Insights into diversity and inheritance of traits involved in multitrophic interactions. PLoS Genet. 7:e1002784.

Martinez-Granero, F., Navazo, A., Barahona, E., Redondo-Nieto, M., Rivilla, R. and Marin, M. 2012. The Gac-Rsm and SadB signal transduction pathways converge on $\mathrm{AlgU}$ to downregulate motility in Pseudomonas fluorescens. PLOS ONE 7:e31765.

Martinez-Granero, F., Rivilla, R. and Martin, M. 2006. Rhizosphere selection of highly motile phenotypic variants of Pseudomonas fluorescens with enhanced competitive colonization ability. Appl. Environ. Microbiol. 72:3429-3434.

Mukherjee, A. and Lutkenhaus, J. 1998. Dynamic assembly of FtsZ regulated by GTP hydrolysis. EMBO J. 17:462-469.
Murray, T. S. and Kazmierczak, B. I. 2013. FlhF is required for swimming and swarming in Pseudomonas aeruginosa. J. Bacteriol. 195:1051-1060.

Navazon, A., Barahona, E., Redondo-Nieto, M., MartinezGranero, F. and Rivilla R. 2009. Three independent signalling pathways repress motility in Pseudomonas fluorescens F113. Microbiol. Biotech. 2:489-498.

Oh, S, A., Kim, J. S., Park, J. Y., Han, S. H., Dimkpa, C., Anderson, A. J. and Kim, Y. C. 2013. The RpoS sigma factor negatively regulates production of IAA and siderophore in a biocontrol rhizobacterium, Pseudomonas chlororaphis O6. Plant Pathol. J. 29:323-329.

O’Toole, G. A. and Kolter, R. 1998. Flagellar and twitching motility are necessary for Pseudomonas aeruginosa biofilm development. Mol. Microbiol. 30:295-304.

Park, J. Y., Oh, S. A., Anderon, A. J., Neiswender, J., Kim, J.-C. and Kim, Y. C. 2011. Production of the antifungal compounds phenazine and pyrrolnitrin from Pseudomonas chlororaphis O6 is differentially regulated by glucose. Lett. Appl. Microbiol. 52:532-537.

Poritsanos, N., Selin, C., Fernando, W. G., Nakkeeran, S. and de Kievit, T. R. 2006. A GacS deficiency does not affect Pseudomonas chlororaphis PA23 fitness when growing on canola, in aged batch culture or as a biofilm. Can. J. Microbiol. 52:1177-1188.

Rashid, M. H., Rao, N. N. and Kornberg, A. 2000. Inorganic polyphosphate is required for motility of bacterial pathogens. J. Bacteriol. 182:225-227.

Schmidt-Eisenlohr, H., Gast, A. and Baron, C. 2003. Inactivation of gacS does not affect the competitiveness of Pseudomonas chlororaphis in the Arabidopsis thaliana rhizosphere. Appl. Environ. Microbiol. 69:1817-1826.

Schniederberend, M., Abdurachim, K., Murray, T. S. and Kazmierczak, B. I. 2013. The GTPase activity of FlhF is dispensable for flagellar localization, but not motility, in Pseudomonas aeruginosa. J. Bacteriol. 195:1051-1060.

Spencer, M., Ryu, C.-M., Yang, K.-Y., Kim, Y. C., Kloepper, J. W. and Anderson, A. J. 2003. Induced defence in tobacco by Pseudomonas chlororaphis strain O6 involves at least the ethylene pathway. Physiol. Mol. Plant Pathol. 63:27-34.

Verstraeten, N., Braeken, K., Debkumari, B., Fauvart, M., Fransaer, J., Vermant, J. and Michiels, J. 2008. Living on a surface: swarming and biofilm formation. Trends Microbiol. 16:496-506. 